\title{
Nos meandros das políticas públicas: a biblioteca escolar em (dis)curso ${ }^{1}$
}

\author{
In the public policies' meanders: the library school in discourse
}

\begin{abstract}
Ludmila Ferrarezi
Doutora em Ciências e Bacharel em Ciências da Informação e da Documentação e Biblioteconomia pela Faculdade de Filosofia, Ciências e Letras de Ribeirão Preto da Universidade de São Paulo E-mail: ludmila.ferrarezi@gmail.com
\end{abstract}

Lucília Maria Abrahão e Sousa

Livre-docente em Ciência da Informação pela Faculdade de Filosofia, Ciências e Letras de Ribeirão Preto -

FFCLRP/USP.

Docente do curso de Ciências da Informação e da Documentação e Biblioteconomia e da Pós-Graduação em

Psicologia da FFCLRP/USP.

E-mail: luciliamsr@uol.com.br

\section{Resumo}

O objetivo deste artigo é investigar como as bibliotecas escolares são discursivizadas no âmbito das políticas públicas brasileiras que (supostamente) as tem como foco, chamando a atenção para a falta e o equívoco que perpassam o discurso bem como tais iniciativas. Nós buscamos também analisar, a partir da perspectiva da Análise do Discurso de linha francesa, a lei no 12244/2010 (que visa à universalização das bibliotecas em todas as instituições de ensino do país), de modo a investigar como a memória discursiva sustenta a retomada de alguns dos sentidos já-ditos sobre essa instituição, os quais foram constituídos por meio de relações de força que permitem a sua naturalização e, também, se os discursos que circulam nesse documento apontam para uma mudança na maneira como a biblioteca foi enunciada até então, possibilitando a emergência de novas posições discursivas, outros sentidos que carregam a promessa de novas possibilidades para as bibliotecas escolares.

Palavras-chave: Biblioteca Escolar; Políticas públicas; Discurso; Lei n. 12.244/2010

\begin{abstract}
The aim of this article is to investigate how the school libraries are put in discourse within the brazilian public policies that (supposedly) have them as focus, highlighting the lack and misunderstanding that go trough the discourse and such initiatives. We also analyzed, from the perspective of french discourse analysis, the law $n^{\circ}$. $12244 / 2010$ (which aims at universalisation of libraries in all educational institutions in the country) in order to investigate how the discursive memory supports the return of some meanings which have already said about this institution, meanings constructed by power relations that allow them naturalization, besides researching if the discourses that circulate in this document point to a change in how the library has been stated so far, allowing the emergence of new dicursive positions, other meanings that bring the promise of new possibilities for the school libraries.
\end{abstract}

Key-words: Scholar library; Public policies; Discourse; Law nº. 12.244/2010

\footnotetext{
${ }^{1}$ Pesquisa realizada com o apoio da FAPESP- Fundação de Amparo à Pesquisa do Estado de São Paulo
}

Bibl. Esc. em R., Ribeirão Preto, v. 3, n. 1, p. 73-88, 2014. 


\section{Considerações iniciais}

Nesse artigo, enfocaremos, a partir do olhar da Análise do discurso de linha pêcheuxtiana, os efeitos de sentido suscitados pelas políticas públicas que historicamente vem sendo destinadas às bibliotecas escolares brasileiras, destacando a falta e o equívoco que os constituem. Para tanto, apresentaremos, inicialmente, algumas considerações sobre a teoria discursiva, que embasará nossas reflexões e análises, destacando os conceitos de memória discursiva, discurso, condições de produção, sujeito, ideologia e a noção de político que, para essa corrente teórica, está relacionada às relações desiguais de poder que sustentam a (re)produção e (des)naturalização de determinados sentidos. Por fim, faremos uma breve análise da Lei $n^{\circ} 12.244$ de 24/05/2010- que "dispõe sobre a universalização das bibliotecas nas instituições de ensino do País" (BRASIL, 2010), perscrutando os sentidos de biblioteca escolar nela circulantes.

\section{Análise do Discurso: o político na linguagem}

Ao ser gestada na efervescência dos anos 1960, marcados por grandes transformações de ordem político-histórica e cultural, a Análise do Discurso ganhou contornos flexíveis, fronteiras menos rígidas que se abriram às fecundas articulações teóricas com diferentes campos do saber, diversos estudiosos que contribuíram para sua formulação, tanto ao participarem ativamente das discussões fomentadas por Michel Pêcheux e o grupo reunido em torno dele (no qual se destacavam Paul Henry e Michel Plon), quanto ao incitarem tais debates, através de suas obras, promovendo polêmicas que resultaram em instigantes trajetos de aproximações e desencontros, explorados com avidez.

É o próprio Pêcheux (2002, p. 45) quem destaca o caráter inovador e subversivo dessa sua (re)elaboração teórica, que se constituiu um "desafio intelectual engajando a promessa de uma revolução cultural, que coloca em causa as evidências da ordem humana como estritamente bio-social", as certezas científicas de cunho positivista, através de uma articulação entre as propostas de Ferdinand de Saussure, Karl Marx e Sigmund Freud que permitiu a emergência de:

novos conceitos (sujeito, História, língua) e deles vai derivar o objeto 'discurso', tensionado por uma relação entre esse novo 'estruturalismo' (releitura de Saussure), um novo 'marxismo' (releitura de Marx) e uma nova teoria do sujeito (releitura de Freud) [...] Por operarem esses deslocamentos (nos conceitos de estrutura, de sujeito, 
de história), esses trabalhos receberam o rótulo de pós-estruturalistas', exatamente para acentuar as diferenças com aquilo que seria um 'estruturalismo formalista'. (GREGOLIN, 2004, p. 25-26)

Sendo assim, por meio de uma confluência teórica caracterizada pela diversidade, os questionamentos, debates, rupturas e reestruturações impulsionaram a construção das bases da teoria do discurso, sem nunca assentá-la em um terreno plano, estabilizado, de certezas inquestionáveis, verdades supremas. Esse caráter volátil e movediço, que também constitui o discurso, foi flagrado, especialmente, na obra do filósofo Michel Pêcheux que, segundo Maldidier (2003, p. 15), "não construiu no firme. Ele é bem o homem dos andaimes, suspensos".

Ressaltamos que a adoção de uma postura metodológica marcada pela redefinição dos limites e conceitos das Ciências Sociais implica o estabelecimento de relações nada pacíficas, jogos de força e embates teóricos atravessados por um forte caráter político, que revestiu a Análise do Discurso desde seu início e que marca todo ato de linguagem, visto que, segundo Guimarães (2005, p.8), "enunciar é uma prática política em um sentido muito preciso", devendo ser pensada histórico-ideologicamente.

Conforme nos conta Orlandi (2005, p. 10), a relação entre o político e o simbólico é central na Análise do Discurso, que se configura como uma teoria que nos permite “compreender como as relações de poder são significadas, são simbolizadas." Na concepção de Lagazzi-Rodrigues (1998, p. 43), o político corresponderia ao "espaço de relações que necessariamente se constituem enquanto relações de força instituindo um domínio de poder, em que há possibilidade de se pensar a mudança.". Nesse espaço tenso, "os sentidos são divididos, não são os mesmos para todo mundo, embora 'pareçam' os mesmos” (ORLANDI, 2010, p. 12 apud DIAS; COUTO, 2011, p. 636). Assim sendo, os princípios formulados por Michel Pêcheux podem ser mobilizados para analisar a textualização do político, sendo necessário levar em conta a luta de classes, a desigualdade de acesso aos poderes e saberes, desmistificando, para tanto, os sentidos aparentemente óbvios, transparentes ou únicos, como, por exemplo, aqueles circulantes nos documentos que enfocam as políticas públicas destinadas às bibliotecas. Segundo Pêcheux (1996, p. 143), a luta de classes "perpassa o modo de produção como um todo, o que, no campo da ideologia, significa que ela 'passa' pelo que 
Althusser chamou de Aparelhos Ideológicos de Estado", atravessando, assim, a constituição ideológica dos sentidos.

Gregolin (2004) menciona que, a partir das teses althusserianas acerca dos aparelhos ideológicos e do assujeitamento, propôs-se a noção de um sujeito constituído pela ideologia e o inconsciente. Deste modo, os conceitos (re)formulados por Althusser foram mobilizados, por Michel Pêcheux, para refletir sobre ideologia, sujeito, discurso e sentido, através de uma articulação com a Linguística e a Psicanálise. Por meio dessas relações interdisciplinares foi possível constituir uma teoria não-subjetiva do sujeito, ou seja, "em que ele não se apresenta como origem de si" (ORLANDI, 2009, p. 3), nem como o seu dono, aquele que controla os seus dizeres, os quais são afetados pela trama sócio-histórica em que eles são constituídos, bem como pela memória discursiva que nos atenta para o fato de que falamos com palavras que já foram ditas, filiando-nos a determinadas regiões do já-lá para compor sentidos que não são transparentes nem literais, podendo sempre serem ressignificados pelos sujeitos, dado o caráter polissêmico da linguagem, ainda que se tente controlá-la, pois algo sempre escapa e falha.

Após essa primeira abordagem teórica, traremos, a seguir, algumas considerações acerca de como a biblioteca escolar vem figurando (ou não) nas políticas públicas, quais sentidos, atravessados sempre pelo político e o ideológico, vem sendo atualizados, pela memória discursiva, para significar essa instituição.

\section{A biblioteca escolar nas políticas públicas: rastros de memória e esquecimento}

A partir de pesquisas que realizamos nos últimos anos, podemos considerar que, sustentadas por um funcionamento discursivo que associa à biblioteca os sentidos de acervo e/ou mero espaço físico, as iniciativas governamentais referentes à (suposta) manutenção e criação de bibliotecas escolares têm girado, especialmente, em torno da distribuição de livros. Essa prática foi iniciada na década de 1930 e tratada mais especificamente pelas políticas públicas, somente a partir dos anos 1980, embora isto não tenha significado a sua

\footnotetext{
${ }^{2}$ É oportuno apontarmos que, a partir da ótica althusseriana, os aparelhos ideológicos (dentre os quais podemos citar a escola, a família, a igreja, os partidos políticos, a mídia, etc.) constituem, para a Análise do Discurso de linha pecheutiana, o palco em que ocorre a luta de classes- que perpassa o modo de produção como um todo- e as condições ideológicas de transformação das relações de produção, já que esses aparelhos não são "puros instrumentos da classe dominante, máquinas ideológicas que reproduzem pura e simplesmente as relações de produção existentes" (PÊCHEUX, 1997, p. 145), havendo espaço, também, para a contradição.
} 
generalização, já que nem todas as escolas eram atendidas e não havia uma periodicidade. (PAIVA, 2009). Para nós, tais políticas, apesar de terem sua importância, são tão restritas quanto a concepção de biblioteca escolar que (as) sustentam, pois elas não contemplam nenhum outro aspecto além da doação, não importando se e/ou como tais livros serão recebidos e utilizados, conforme nos conta Arena (2009, p. 180):

destinam recursos para a compra e distribuição de livros de literatura nas escolas, mas duas outras situações não são contempladas: nenhuma atenção é dada para os poucos educadores de bibliotecas, nem para os espaços físicos da biblioteca, e a mais intensa ou menos intensa presença da literatura fica à mercê das decisões isoladas de docentes.

Assim sendo, as políticas públicas, que insistem em reunir, mas não em dispersar as obras doadas, deixam tal encargo às escolas, aos professores, já que a presença do bibliotecário ainda não foi difundida nas escolas brasileiras, especialmente as da rede pública de ensino. Deste modo, segundo Paiva (2009, p. 150):

\footnotetext{
quando não se investiga a visibilidade, o grau de conhecimento, a capilaridade dessas políticas no chão da escola, desconsiderando em que medida e de que maneira esses materiais são recebidos e usados pelos profissionais da escola, esvazia-se uma ação que poderia repercutir enormemente, no processo de formação de leitores.
}

Configurando-se desta maneira pouco profícua, tais ações podem ser vistas como distributivistas, "ou seja, trata os bens culturais como se fossem merenda, giz, lápis, borracha, sem considerar a dimensão simbólica dos bens culturais (os livros) que distribui e sua natureza especifica." (PERROTTI; VERDINI, 2008, p. 15). Apesar de indispensáveis, acreditamos que a simples distribuição de livros não contribui para a formação de leitores, pois "somente com livros silenciosos e sonolentos no escuro silencioso dos espaços eventualmente abertos, a leitura não nasce, porque quem a faz nascer e existir são seus leitores com a mediação dos educadores de biblioteca. A leitura do livro de literatura não preexiste ao leitor: é criada por ele" (ARENA, 2009, p. 164).

Como o foco totalmente voltado para as atividades de distribuição de livros, menosprezam-se as questões relacionadas às condições necessárias para que o acervo seja posto em movimento e não fique abandonado em bibliotecas que funcionam como depósitos de livros e outros materiais não utilizados. Assim sendo, "o grande desafio a ser vencido é combinar a política de distribuição de livros com outras ações, tais como, dinamização dos espaços de leitura, implantação de centros de leitura multimídia, formação de professores como mediadores de leitura" (BEAUCHAMP; SILVA, 2007, p. 4). 
A respeito dos acervos das bibliotecas escolares, destacamos sua constante precariedade, ao serem formados, quase que totalmente, pelas obras impressas doadas pelos governos, as quais, muitas vezes, não são suficientes e nem interessantes para os sujeitosleitores, o que as leva amiúde a permanecerem fechadas nas estantes, não sendo abertas uma única vez. Sendo assim, observamos, assim como Almeida Júnior (2006), a falta de uma política de desenvolvimento de coleções, por meio da qual se abandona "a acumulação pura e simples do material em benefício da possibilidade de acesso ao mesmo, tornando a coleção consistente com as metas e objetivos da instituição a que serve" (VERGUEIRO, 1993, p. 15); sendo importante também que esse acervo vá ao encontro dos anseios dos sujeitos-leitores, que poderão então soprar a poeira, pôr a biblioteca em movimento.

Consideramos, também, que o simples recebimento de um acervo doado não significa necessariamente a valorização da biblioteca, visto que ele pode não ser suficiente e nem concernente às particularidades e necessidades de cada escola, sendo necessário, primeiramente, que a biblioteca exista, com uma estrutura mínima adequada e profissionais preparados para mediarem as obras, instituírem projetos e atividades que aproximem a biblioteca de seus sujeitos-leitores e que façam dessa instituição um:

\begin{abstract}
espaço discursivo em que todos estes sujeitos possam construir sentidos sobre a linguagem e o mundo, em que as páginas dos impressos e as telas eletrônicas possam ser permanentemente ressignificadas por outros sentidos em movimentos espiralados de manutenções ou deslocamentos [...] um espaço de circulação de diferentes sujeitos e discursos que se cruzam e atravessam no processo de produção de sentidos na escola. (FERRAREZI, 2007, p. 35).
\end{abstract}

Deste modo, frisamos que a distribuição do acervo não equivaleria à "universalização do acesso" e do conhecimento, pois é necessário levar em conta se e como as obras distribuídas são lidas e interpretadas, e não a sua simples existência, a soma total de livros presentes em uma biblioteca. Conforme nos conta Paiva (2009, p. 150), essas questões ligadas à recepção e uso dos livros de literatura distribuídos por esses programas governamentais não são consideradas nas pesquisas, assim como:

\footnotetext{
são escassas as ações governamentais que visam ultrapassar a distribuição pura e simplesmente desses materiais. Ocorrem com menor frequência, ainda, as ações que viabilizam a formação de professores e profissionais que atuam nas bibliotecas escolares para o reconhecimento do potencial do material disponibilizado e suas possibilidades educativas no cotidiano escolar, em especial, na sala de aula e na biblioteca.
}

Realizadas de forma simplista, as ações de distribuição de livros não se convertem em um processo de formação de leitores críticos. É preciso "exercitar a análise crítica de cada obra selecionada, quando essa for posta em circulação, em uso e recepção nos espaços 
escolares” (PAIVA, 2009, p. 153), o que, para nós, implica considerar as condições sóciohistórico-ideológicas de produção do discurso, a memória e as relações desiguais de poder, poder dizer e saber. Segundo a autora, apesar das críticas ao PNBE (Programa Nacional Biblioteca da Escola), "os acervos estão chegando nas escolas e a melhor maneira de refletir sobre o seu potencial, e a sua adequação, é colocá-los em uso, da maneira mais consistente e problematizadora possível." (PAIVA, 2009, p. 153). Assim sendo, reconhecemos que tais programas de distribuição de obras são importantes, mas que devem ser vistos como inicio e não o fim das ações em prol da leitura e valorização das bibliotecas.

Ressaltamos que essas ações político-governamentais, ao considerarem que a distribuição de livros é a solução, minimizam e simplificam os problemas relacionados, por exemplo, ao interesse pela leitura e à atuação e visibilidade das bibliotecas, agravando-os, pois são apagadas as discussões e reflexões que poderiam culminar em práticas mais frutíferas. Essa situação que descrevemos até aqui representa um quadro de dificuldades e restrições ainda recorrente, que sustenta tanto a produção de alguns sentidos de biblioteca escolar- que vão de encontro aos que são considerados ideais, por órgãos como International Association of School Librarianship ${ }^{3}$ e International Federation of Library Association and Institutions ${ }^{4}$-, quanto a emergência de novas intervenções jurídicas que pretendem mudar esse panorama, como é o caso da Lei $n^{\circ} 12244 / 2010$ sobre a qual teceremos, a seguir, alguns movimentos de análise, indagando se os sentidos de biblioteca presentes nesse documento apontam (ou não) para uma mudança na maneira como ela foi discursivizada até então, de modo a romper com o mesmo, instalando o diferente, o acontecimento (PÊCHEUX, 2002).

\section{A biblioteca escolar no discurso da lei: entre o repetível e o diferente}

Ao falarmos sobre como a biblioteca escolar é importante indagarmos que sentidos tal termo evoca: se aqueles que a associam a locais apropriados, agradáveis, vivos, habitados por livros e outros materiais, que são postos em circulação por profissionais e alunos, ou, por outro lado, os que a enunciam como uma sala fechada, um amontoado de livros? Consideramos que tais questionamentos não estão presentes nas pesquisas

\footnotetext{
${ }^{3}$ Cf. INTERNATIONAL ASSOCIATION OF SCHOOL LIBRARIANSHIP. Declaração Política da IASL sobre Bibliotecas escolares. 1993. Disponível em: <http://www.oei.es/pdfs/rbe5.pdf>. Acesso em: 18 nov.2011.

${ }^{4}$ Cf. INTERNATIONAL FEDERATION OF LIBRARY ASSOCIATION AND INSTITUTIONS. Manifesto IFLA/UNESCO para biblioteca escolar. São Paulo: [s.n.], 1999. Disponível em: $<$ http://www.ifla.org/VII/s11/pubs/portuguese-brazil.pdf>. Acesso em: 18 nov.2011.
} 
realizadas, sendo difícil traçar um paralelo sobre as condições das bibliotecas escolares quando elas estão inseridas em um contexto sócio-histórico em que se considera que a simples existência de um espaço e uma coleção, quase sempre restrita aos livros doados por programas governamentais, seria o suficiente para haver uma biblioteca figurando (ou não) nas pesquisas. E é por irmos de encontro a essa forma simplista de conceber a biblioteca escolar, que desconsidera a opacidade e pluralidade do discurso, que não podemos (nem queremos) fazer uma leitura literal e ingênua dos sentidos que circulam sobre esta instituição, nem considerarmos que é possível a objetividade da linguagem, a qual é reforçada pelas estatísticas, tão utilizadas no discurso político, científico e midiático:

Ao apresentar o número como prova contundente, o sujeito desse discurso produz o
sentido de certificação, de conhecimento da realidade [...] o uso do número põe em
funcionamento o sentido de exatidão e de mapeamento seguro e comprovado dos
fatos, do qual o leitor não ousaria discordar, visto que, como já dissemos, há no
número o efeito ideológico de um dado irrefutável. (FERRAREZI; ROMÃO, 2006,
p. web)

Deste modo, como já sinalizamos, é importante abordarmos a biblioteca escolar de forma mais crítica, duvidando da transparência da linguagem e buscando considerar a ideologia e as relações de poder que influenciam a constituição dos discursos sobre a biblioteca. Tal postura nos leva a superar uma visão ingênua, por meio da qual se pode pensar, por exemplo, que a Lei $n^{\circ} 12244$ de 24/05/2010 seria a garantia de uma solução derradeira para os problemas enfrentados pelas bibliotecas escolares brasileiras.

Antes de falarmos um pouco a respeito desta lei, é importante destacarmos que os dizeres oficiais sobre a biblioteca escolar ocupam uma suposta posição de autoridade, prestígio e veracidade, a partir da qual são recortadas algumas regiões da memória, naturalizadas como os únicos sentidos passíveis de circulação e legitimação, enquanto outras são silenciadas; a partir desse lugar de aparente onipotência e completude, a lei é tida como transparente, apagando a ideologia e as relações de força que afetam a produção dos discursos considerados, nesta perspectiva, como sendo evidentes.

A partir do exposto, observamos nessa lei a pretensão de universalizar o acesso à biblioteca escolar, ou seja, disponibilizá-la a todos igualmente, imbuindo-se, para tanto, de poder suficiente para garantir, apenas pela escrita da lei, a concretização do que foi proposto, conforme podemos observar nestes recortes (BRASIL, 2010, p. 3, grifos nossos): "as instituições de ensino públicas e privadas de todos os sistemas de ensino do País, contarão com bibliotecas, nos termos desta Lei”, "será obrigatório", “universalização 
das bibliotecas escolares, nos termos previstos nesta Lei”. Conforme já adiantamos, consideramos pertinente, ao se tratar do tema, a discussão de algumas questões que não são trazidas pelo discurso da lei, tais como: que biblioteca é essa a qual todos devem ter acesso?; como a lei irá garantir tal acessibilidade?; quais pessoas serão responsáveis por tal empreitada?; que novas possibilidades de atuação podem ser vislumbradas?, dentre outros questionamentos que nos levam a apontar a falta que constitui todo discurso e, ao mesmo tempo, a ilusão da completude do sujeito, que é dada pelo esquecimento número dois, proposto por Pêcheux (1997), e diz respeito à crença do sujeito de que o modo como ele enuncia, constitui o seu discurso, é o único possível.

Levando em conta essa impossibilidade de tudo dizer e os caminhos que nos dispusemos a percorrer nesse texto, é preciso dizer que não temos a pretensão de responder a todas essas questões, entretanto, podemos inferir que, do nosso ponto de vista, a referida lei não diz respeito à criação de verdadeiras bibliotecas tal como as concebemos, pois faz retornar, pela memória discursiva, sentidos que as significam de forma limitada, como sinônimo de acervo, conforme podemos observar no seguinte recorte "para os fins desta lei, considera-se biblioteca escolar a coleção de livros, materiais videográficos e documentos registrados em qualquer suporte destinados a estudo, consulta, pesquisa, estudo ou leitura" (BRASIL, 2010, p. 3, grifos nossos). Consideramos que se a tão parafraseada equação lingüística (SOARES, 2006) supracitada "biblioteca = acervo" não fosse atravessada pela opacidade, o equívoco e a falta, as políticas de distribuição de obras empreendidas há anos pelos governos sustentariam outros efeitos de sentido para as bibliotecas escolares, que não os de inacessibilidade, inexistência e precariedade, posto que os problemas relacionados a essa instituição já teriam sido resolvidos ao longo de várias ações, como as que foram empreendidas pelo PNBE (Programa Nacional Biblioteca da Escola).

É importante frisar, também, que as medidas impostas pela lei referem-se apenas à existência dessas obras e à sua ordenação e conservação, conforme observamos no excerto: “será obrigatório um acervo de livros na biblioteca de, no mínimo, um título para cada aluno matriculado, cabendo ao respectivo sistema de ensino determinar a ampliação deste acervo conforme sua realidade, bem como divulgar orientações de guarda, preservação, organização e funcionamento das bibliotecas escolares". (BRASIL, 2010, p. 3, grifos nossos). Portanto, não são apontados quaisquer outros aspectos que julgamos relevantes, tais como as atividades de caráter literário, lúdico e pedagógico, a inclusão da biblioteca no 
projeto pedagógico da escola, planejamento orçamentário para colocar em movimento uma biblioteca mais dinâmica, com diversos materiais e recursos, etc., exigindo-se apenas a quantidade de obras a serem providenciadas.

Não podemos ignorar a importância de ter sido aprovada uma lei referente à biblioteca escolar, visto que o apagamento da mesma no discurso político e jurídico impossibilita ações estruturadas, planejadas a longo prazo. Contudo, apesar da biblioteca escolar ocupar, nesse documento, uma nova posição discursiva- de destaque, pela qual se busca tamponar os sentidos dominantes de ausência e restrição, rompendo com o seu silenciamento na esfera da lei-, temos, pelo caráter político e contraditório da linguagem, um embate de sentidos, por meio do qual ela ainda é vista, no âmbito do autoritário discurso jurídico, de forma limitada, ao serem atualizados alguns sentidos circulantes desde o início da história das bibliotecas, que as discursivizam como um lugar imóvel, um simples depósito. Deste modo, concordamos com Perrotti (2008, p. 2) e sua afirmação de que:

Para superar condições de mero entreposto e tornar-se espaço de cultura vivo,
dinâmico, atrativo, a biblioteca não pode simplesmente existir, entregando ao acaso
sua dinamização. É preciso atuar, agir, criar metodologias e estratégias compatíveis
com projetos históricos empenhados em reverter o quadro de exclusão que sempre
marcou a vida nacional; é preciso combinar opções de políticas públicas inclusivas
com práticas culturais da mesma natureza, criando-se uma dinâmica entre macro e
micro ações visando à participação e inclusão de todos nos processos de
conhecimento e cultura

Entendemos que uma adequada estrutura pode contribuir para que outras práticas sejam implementadas, visto que o estabelecimento de uma biblioteca em salas de aula adaptadas inibe, segundo Furtado (2004) e Antunes (1998), o seu pleno funcionamento e continuidade, pois, a qualquer momento, por falta de espaço, estas salas podem ser desativadas- o que nos leva a dizer que a biblioteca escolar ainda se encontra em um longo estado de provisoriedade que, sustentado pela inércia do poder público, dificulta a superação dos problemas que a afetam. Segundo Silva e Bortolin (2006, p. 14), trata-se de "uma verdadeira improvisação que pode refletir no entendimento e no desejo de permanecer nesse ambiente", que se localiza, muitas vezes, no pior espaço, mal iluminado, contando com um mobiliário formado por tudo o que sobrou de outras repartições. —— Há casos em que a biblioteca divide seu espaço com materiais de limpeza e entulho, não permanecendo aberta para seus leitores, por falta das mínimas condições que permitissem seu funcionamento, a mediação de livros, que permanecem guardados, empoeirados nas estantes, conforme nos conta Arena (2009, p. 163): 
livros guardados em cubículos mal iluminados, a conviver com baldes e panos de chão, ou guardados, e muito bem, a portas fechadas, por falta de quem os pudesse guardar junto aos livros de registro, com olhos atentos.

É interessante observamos que este descaso, presente ainda em muitas escolas, é promovido primeiramente pelo Estado, mas, depois, a instituição escolar acaba reproduzindo a estrutura estatal de desprestígio à leitura e à biblioteca (SILVA; BORTOLIN, 2006), reforçando os sentidos restritos já-ditos e repetidos sobre ambas. Este desprezo dos governos pela biblioteca pode ser percebido no longo período de "inexistência de um programa definido de implantação e implementação de bibliotecas escolares. Assim, o funcionamento das bibliotecas nas escolas fica dependente das ações da própria escola" (FURTADO, 2004, p. 3), as quais se configuram como precárias, visto que são fragmentadas, esporádicas. Essa situação confirma a importância de uma lei que respalde a criação de bibliotecas e, ao mesmo tempo, de ações que as coloquem em movimento, driblando a falta de planejamento, que foi e ainda é um dos grandes entraves ao desenvolvimento das bibliotecas, visto que:

mesmo uma super biblioteca escolar, se não tiver um projeto de desenvolvimento,
acaba cristalizando-se e morrendo de inanição. Apesar das dificuldades, sempre é
possível articular recursos, criar conexões, lançar mão e otimizar as possibilidades
por mínimas que estas sejam; por outro lado, sempre é possível aumentar as chances
de um trabalho significativo ao se buscar cooperação, trocas, comunicação; sempre é
possível, enfim, inventar, criar, ampliar, ao se estabelecer elos. (PERROTTI;
VERDINI, 2008, p. 21)

Tal assertiva nos leva a considerar que, diante de um contexto marcado por grandes dificuldades, é importante que a biblioteca escolar conte com um profissional que permita a emergência de práticas mais polissêmicas que a ressignifiquem. Marcamos aqui que a necessidade de um profissional preparado e também motivado para atuar nas bibliotecas não é comumente satisfeita na grande maioria das escolas do país, nas quais o bibliotecário ainda não é reconhecido, não faz parte do quadro de funcionários públicos, o que vai de encontro ao proposto pela Lei $\mathrm{n}^{\circ} 12244$, que, estabelecendo um prazo máximo de dez anos para a sua aplicação, prevê que seja "respeitada a profissão de Bibliotecário" (BRASIL, 2010). Fragoso (2002, p. 126) nos alerta para o fato de que, inclusive nas instituições privadas, é constatada a ausência do bibliotecário:

Mesmo aquelas que podem se dar o luxo de algum aparato tecnológico e de práticas mais modernas relutam em investir nos recursos humanos, deixando que alguns velhos cacoetes culturais perdurem. Por exemplo, o de improvisar um guardião que terá como missão, de fato, guardar o geralmente precário material bibliográfico. E o fará, geralmente também, com um zelo e uma rabugice de burocrata. Os leitores da assim chamada biblioteca - crianças e adolescentes, em sua maioria - irão frequentála com igual despreparo e desinteresse, sub-utilizando sempre os possíveis recursos. 
E o contato prazeroso com a leitura - já de si tão problemático nestes tempos de cultura visual -, este sim, passa por metamorfose definitiva: ler se torna mais um entre os deveres escolares.

É muito frequente que no lugar dos bibliotecários sejam empregados professores denominados "readaptados", que são aqueles com problemas de saúde, afastados da sala de aula, pra onde retornam após o tratamento. Há também o caso de professores que ficam nas bibliotecas enquanto aguardam a aposentadoria ou outra oportunidade de trabalho e outros ainda são leigos (ANTUNES, 1998; SILVA, 2003). Assim como Furtado (2004, p. 4), consideramos que estes "não são os profissionais indicados para atuarem nas bibliotecas escolares, como é prática da realidade brasileira".

O próprio termo "readaptado" inscreve sentidos de desajuste perante um determinado contexto ou situação vista como estranha, inadequada, mas na qual será preciso encaixar-se "acomodar-se", não sem dificuldades. Pela força da repetição, este termo nos parece estar naturalizado, ser óbvio dizer "professor readaptado", "professor de biblioteca", ou ainda, "professor-bibliotecário", em vez de "bibliotecário", como se todos estes termos fossem sinônimos, apagando a reflexão acerca dos mesmos, silenciando o sujeito-bibliotecário (cuja falta comumente não suscita mais estranhamento) e a própria indolência do governo em relação à biblioteca escolar que, por esse ângulo, poderia receber qualquer funcionário, não sendo importantes sua qualificação, disposição ou até mesmo condições de saúde adequadas para poder exercer as atividades, assim como o treinamento, planejamento das ações a serem implementadas ou ainda um plano de carreira. Sendo assim, a biblioteca seria vista mais como um depósito para funcionários, materiais e alunos indesejáveis em outros espaços, teria seu conceito deturpado, como nos conta Baró, Maña e Vellosillo (2001, p. 11): “es muy habitual en los centros colocar en la biblioteca a la persona que por algún motivo no puede ocuparse de un grupo de alumnos. Eso demuestra el concepto erróneo que se tiene de ella, a la que ven como un sitio de retiro, sin niños y con un trabajo tranquilo".

É importante lembrarmos ainda que uma atuação problemática e infrutífera nas bibliotecas não é exclusividade de profissionais não habilitados em Biblioteconomia/Ciência da Informação, já que muitos bibliotecários não estão preparados para atuar frente às particularidades da biblioteca escolar, que contém objetivos muito diferentes das demais bibliotecas, não devendo ser vistas a partir de uma ótica instrumentalista, onde, segundo Castán $^{5}$ (2002 apud BAJOUR, 2007, p. 1), “os meios se confundem com os fins, e evitando o

\footnotetext{
${ }^{5}$ CASTÁN, Guillermo. Bibliotecas escolares: soñar, pensar, hacer. Sevilla, Espanha: Díada, 2002.
} 
debate de fundo, que deveria centralizar-se nas finalidades, no para que (e somente depois se responderia ao como) de uma biblioteca escolar de novo cunho.", acessível, presente, não apenas no discurso da lei, mas no dia-a-dia das escolas e da comunidade.

Diante desse quadro, consideramos importante que os profissionais bibliotecários, assim como educadores e outros setores da população, mobilizem-se em prol de que o poder público reconheça a necessidade de investir em uma escola de qualidade, o que implica a existência e ativação de bibliotecas (e não depósitos de livros doados), guiadas por uma equipe multidisciplinar e preparada de profissionais que, a partir de seu empenho e apoio político-institucional, poderiam empreender ações que desafiem e superem as dificuldades que perpassam a educação no Brasil. Através dessas iniciativas, seria possível unir esforços para que as bibliotecas não fiquem estagnadas e fechadas por falta de alguém que nelas atuem, para que haja um profissional consciente do importante papel que a biblioteca é chamada a desempenhar e com condições e disposição para realizar um trabalho que vai muito além da guarda, organização e empréstimo do acervo, de forma contínua, planejada e em consonância com a realidade escolar. Deste modo chamar-se-ia a atenção da sociedade para essa instituição que, geralmente fica escondida em algum canto da escola, delineando-se, assim, sentidos que vão além daqueles que historicamente vem sendo produzidos nas esferas jurídicas, governamentais.

Por fim, temos que, a partir da análise da lei que visa à universalização de bibliotecas no país, pudemos observar como a memória discursiva sustenta a retomada de alguns dos sentidos já-ditos sobre essa instituição, que foram constituídos por meio de relações de força que permitem a sua naturalização e, ao mesmo tempo, a sua ruptura, a emergência de novas posições discursivas, outros sentidos que carregam a promessa de novas possibilidades para as bibliotecas escolares. 


\section{Referências}

ALMEIDA JÚNIOR, O. F. Pesquisa escolar: entre o modelo educacional e a liberdade da pesquisa. In: SILVA, R. J.; BORTOLIN, S. (Org.). Fazeres cotidianos na biblioteca escolar. São Paulo: Polis, 2006.

ANTUNES, W. A. Biblioteca escolar no Brasil: reconceituação e busca de sua identidade a partir de atores do processo ensino-aprendizagem. 1998. Tese (Doutorado) - Faculdade de Educação, Universidade de São Paulo, Ribeirão Preto, 1998.

ARENA, D. B. Leitura no espaço da biblioteca escolar. In: SOUZA, R. J. (Org.). Biblioteca escolar e práticas educativas. Campinas: Mercado de Letras, 2009. p. 157-185.

BAJOUR, C. Quando a biblioteca é um assunto de escola. Pensar el libro, n. 5, jan. 2007. Disponível em: <http://www.cerlalc.org/revista_enero/articulo03_p.htm>. Acesso em: $10 \mathrm{dez}$. 2009.

BARÓ, M.; MAÑA, T.; VELLOSILLO, I. Bibliotecas escolares: ¿para qué? Madrid: Anaya, 2001.

BEAUCHAMP, J.; SILVA, J. C. Bibliotecas escolares: a experiência brasileira. Pensar el libro, n. 5, jan. 2007, Disponível em:

$<$ http://www.cerlalc.org/revista_enero/articulo04_p.htm>. Acesso em: 21 ago. 2011.

BRASIL. Lei $n^{\circ} 12244$, de 24 de maio de 2010. Dispõe sobre a universalização das bibliotecas nas instituições de ensino do País. Diário Oficial da União. Brasília, 25 maio 2010. Disponível em: <http://www.jusbrasil.com.br/diarios/5259000/dou-secao-1-25-052010-pg-3>. Acesso em: 17 jul. 2011.

DIAS, C.; COUTO, O. F. As redes sociais na divulgação e formação do sujeito do conhecimento: compartilhamento e produção através da circulação de idéias. Linguagem em (Dis)curso, Tubarão, v. 11, n. 3, p. 631-648, set./dez. 2011. Disponível em:

<http://www3.unisul.br/paginas/ensino/pos/linguagem/1103/110308.pdf>. Acesso em: $20 \mathrm{dez}$. 2011.

FERRAREZI, L. O imaginário sobre a biblioteca escolar: sentidos em discurso. 2007. 106 p. Trabalho de Conclusão de Curso. (Graduação em Ciências da Informação e da Documentação) - Faculdade de Filosofia Ciências e Letras de Ribeirão Preto, Universidade de São Paulo, Ribeirão Preto, 2007.

.; ROMÃO, L. M. S. Discurso jornalístico: efeitos de didatização da realidade.

Observatório da imprensa, ano 12, n. 382, 2006. Disponível em:

<http://www.observatoriodaimprensa.com.br/artigos.asp?cod=382DAC005>. Acesso em: 10 dez. 2011.

FRAGOSO, G. M. Biblioteca na escola. ACB, v. 7, n. 1, 2002. Disponível em: $<$ http://revista.acbsc.org.br/index.php/racb/article/view/380/461>. Acesso em: 10 jul. 2011. 
FURTADO, C. A biblioteca escolar brasileira no sistema educacional da sociedade da informação. In: SEMINÁRIO BIBLIOTECA ESCOLAR: ESPAÇO DE AÇÃO

PEDAGÓGICA, 3., 2004, Belo Horizonte. Anais eletrônicos... Belo Horizonte: Escola de Biblioteconomia da Universidade Federal de Minas Gerais, Associação de Bibliotecários de Minas Gerais, 2004. Disponível em: <http://www.eci.ufmg.br/gebe/? Semin\%E1rios:

III_Semin\%E1rio_Biblioteca_Escolar>. Acesso em: 3 jul. 2011.

GREGOLIN, M. R. Foucault e Pêcheux na análise do discurso: diálogos e duelos. São Carlos: Claraluz, 2004.

GUIMARÃES, E. Semântica do acontecimento: um estudo enunciativo da designação. 2. ed. Campinas: Pontes, 2005.

LAGAZZI-RODRIGUES, S. A discussão do sujeito no movimento do discurso. 1998. Tese (Doutorado em Linguística) - Instituto de Estudos da Linguagem, Universidade Estadual de Campinas, Campinas, 1998.

MALDIDIER, D. A inquietação do discurso: (re)ler Michel Pêcheux hoje. Campinas: Pontes, 2003.

ORLANDI, E. P. Michel Pêcheux e a análise do discurso. Estudos da Língua(gem), Vitória da Conquista, n. 1, p. 9-13, jun. 2005. Disponível em:

$<$ http://www.cpelin.org/estudosdalinguagem/n1jun2005/artigos/orlandi.pdf $>$. Acesso em: 10 ago. 2011.

Claude Lévi-Strauss, Michel Pêcheux e o estruturalismo. Com Ciência, n. 108, 10 maio. 2009. Disponível em:

$<$ http://www.comciencia.br/comciencia/?Section=8\&edição=52\&id=658>. Acesso em: 10 set. 2011.

PAIVA, A. A trama do acervo: a literatura nas bibliotecas escolares pela via do Programa Nacional Biblioteca da Escola. In: SOUZA, R. J. (Org.). Biblioteca escolar e práticas educativas. Campinas: Mercado de Letras, 2009. p. 137-155.

PÊCHEUX, M. O mecanismo do (des)conhecimento ideológico. In: ZIZEK, S. (Org.). Um mapa da ideologia. Rio de Janeiro: Contraponto, 1996. p. 143-152.

Semântica e discurso: uma crítica à afirmação do óbvio. 3. ed. Campinas: Ed. da UNICAMP, 1997.

- O discurso: estrutura ou acontecimento. 3.ed. Campinas: Pontes, 2002.

PERROTTI, E. Sonhos e bibliotecas. Carta Escola, ed. 26, 9 maio. 2008. Disponivel em: $<$ http://www.cartanaescola.com.br/edicoes/26/sonhos-e-bibliotecas >. Acesso em: 10 out. 2009.

.; VERDINI, A. S. Estações do conhecimento: espaços e saberes informacionais. In: ROMÃO, L. M. S. (Org.). Sentidos da biblioteca escolar. São Carlos: Compacta, 2008. p. 13-39. 
SILVA, R. J.; BORTOLIN, S. Reflexões sobre a leitura e a biblioteca escolar. In:

(Org.). Fazeres cotidianos na biblioteca escolar. São Paulo: Polis, 2006.

SILVA, W. C. Miséria da biblioteca escolar. 3. ed. São Paulo: Cortez, 2003

SOARES, A. S. F. A homossexualidade e a AIDS no imaginário de revistas semanais (1985-1990). 2006. 235 f. Tese (Doutorado em Letras) - Universidade Federal Fluminense, Niterói, 2006.

VERGUEIRO, W. C. S. Desenvolvimento de coleções: uma nova visão para o planejamento de recursos informacionais. Ciência da informação, Brasília, v. 22, n. 1, p. 13-21, jul./abr. 1993. Disponível em: <http://revista.ibict.br/index.php/ciinf/article/viewArticle/1208>. Acesso em: 15 set. 2011. 